\begin{abstract}
TOREAN THEK@ S@CIETY

Journal of Electrochemical Science and Technology

\section{Electrochemical Method for Detecting Hippuric Acid Using Osmium-antigen Conjugate on the Gold Nanoparticles Modified Screen-printed Carbon Electrodes}

\author{
Young-bong Choi and Hyug-Han Kim ${ }^{\dagger}$ \\ Department of chemistry, Dankook University, Anseo-dong, Cheonan 330-714, Republic of Korea
}

ABSTRACT :

This paper describes an electrochemical immunoassay for simple, fast and quantitative detection of a urinary hippuric acid which is one of major biological indicator in toluene-exposed humans. The electrochemical system of immunoassay was based on the directly osmium complex conjugated with hippuric acid. With the competition between free hippuric acid (HA) and the osmium-hippuric acid conjugate (Os-HA) to bind with antibody hippuric acid (Anti-HA) coated onto gold nanoparticles, the electrical signals were proportional to urinary hippuric acid (HA) in the range of $0.01-5 \mathrm{mg} / \mathrm{mL}$ which is enough range to be used for in-field or point-of-care (POC) diagnosis. The proposed electrochemical method can be extended to the applications to detect a wide range of different small molecules in the field of health care.
\end{abstract}

Keywords : Immunosensor, hippuric acid, osmium, point-of-care

Received March 2, 2011 : Accepted March 24, 2011

\section{INTRODUCTION}

Hippuric acid (HA) is a major urinary metabolite in toluene-exposed human with a molecular weight of $180 \mathrm{Da}$. Toluene is readily available, widely used for chemical synthesis, paint, thinner, detergents, adhesive, and petroleum industries as a solvent. People chronically exposed to toluene, because of occupation or recreational glue sniffing, have demonstrated anatomical change in the brain and neurobehavioral impairments. ${ }^{1-3)}$ The most frequently reported neurobehavioral changes from toluene exposure are related to cognitive function, including memory. Generally, urinary HA was measured by a colorimetric reaction, gas chromatography (GC), or high performance liquid chromatography (HPLC). ${ }^{4-7)}$ Although these methods have several advantages, low specificity, complicated procedures and slowness, the requirement

Corresponding author. Tel.: +82-41-550-3430

E-mail address: hankim@dankook.ac.kr of large sample volume, and high costs are limitations to be addressed.

Recent progress of technology facilitates immunoassay simpler and faster using small quantity of sample, and several chip-based immunoassay systems have been proposed. However, most of these approaches employ simple optical detection methods, which have some limits in increasing portability for the point-of-care testing of illicit chemicals. ${ }^{8-11)}$ Electrochemical detection method is one of the most attractive systems for simple designed signal generation of immunosensors. In electrochemical immunosensor system, antibodies are mainly used as probe on the solid surface. The major type of immunosensor depends on the capabilities of immobilized antibodies to bind those recognized target which is called as an antigen. The efficient immobilization of antibodies on the solid surface such as assay chip is an essential step in the preparation of these immunosensors using various methods. Most of early electrochemical immunosensors are basically combined with ELISA methods. The amount of labeling enzymes and metal nanoparticles on antibody is proportional to the 
currents. Unlike the optical immunoassay, the electrochemical immunoassay for clinical diagnosis has several advantages such as good selectivity, simple instrumentation, relatively low cost, miniaturization, disposability, and fully automation. $^{12-15)}$

In this paper, we report a simple electrochemical immunosensor for the detection of small molecule, hippuric acid (HA). Most of researchers for the detection of small molecules have studied to label either antibody or antigen with metals or enzyme. For example, Lim and Matsunaga reported ferrocene-conjugated $\mathrm{IgG}$ for detection of histamine and human chorionic gonadotropin (HCG). ${ }^{16-18)}$ Songqin et al. have developed a ferroceneboric acid-based biosensor for glycated hemoglobin. Nam et al. have introduced a novel nanoparticle-based biomarker for detection of prostate specific antigen (PSA). ${ }^{19)}$ Das et al. have developed a gold-nanoparticle-based assay for specific proteins. ${ }^{20)}$ Purushothama and co-workers have reported an alkaline phosphatase-labeled immunosensor system. ${ }^{21)}$ Zhang and Heller have shown a horseradish peroxidase (HRP)-labeled antibody with the electrodebounded redox hydrogel polymers. ${ }^{22)}$

Here we report a simple approach to the performance of the electrochemical immunoassay for the detection of hippuric acid (HA). In our immunoassay, we have directly been conjugated a hippuric acid (HA) with osmium complex (Os) and no further modifications. The retaining hippuric acid conjugated with osmium (Os-HA) is effective with HA-antibody in the electrochemical immunoassay. The electrochemical currents of unbinded HA-Os can be detected through competitive reaction between free HA and HA-Os. The detection limit of our system was at hundredth microgram $/ \mathrm{mL}(>100 \mu \mathrm{g} / \mathrm{mL})$. In practice, this sensitivity of the immunosensor quietly meets the cutoff for direct detection of hippuric acid in the urine.

\section{Experimental Sections}

\section{Materials and Reagents}

A carbon electrode was screen-printed on OHP film (Electrodag 423SS, Acheson, USA) using a screen printing machine (BS-860AP, Bando, Korea). $N$-ethyl$N$-[3-dimethylaminopropyl] carbodiimide (EDC), bovine serum albumin (BSA), N-hydroxy succinimide (NHS), hydrochloric acid, potassium hexachloroosmate(IV) $\left(\mathrm{K}_{2} \mathrm{OsCl}_{6}\right)$, hippuric acid (HA), sodium hydrosulfite, 4,4-dimethyl-2,2-dipyridyl, 4-(aminomethyl)pyridine, and sodium hydrosulfite were purchased from Aldrich (Milwaukee, WI). The phosphate buffered saline solution
(PBS : 4.3 mM NaH $2 \mathrm{PO}_{4}, 15.1 \mathrm{mM} \mathrm{Na} 2 \mathrm{HPO}_{4}, 140 \mathrm{mM}$ $\mathrm{NaCl})$, the washing buffer $\left(4.3 \mathrm{mM} \mathrm{NaH}_{2} \mathrm{PO}_{4}, 15.1 \mathrm{mM}\right.$ $\mathrm{Na}_{2} \mathrm{HPO}_{4}, 500 \mathrm{mM} \mathrm{NaCl}$ and $0.5 \%$ Tween $20^{\circledR}$ ), and all other solutions were prepared using deionized water (Barnstead, Nanopure II, Van Nuys, CA). Monoclonal antibody isotyping Kit I (HRP/ABTS) was purchased from Pierce (Rockford, IL). All other reagents were used without further purification. All solutions were prepared using ultrapure water (18 M , millipore, USA) or autoclaved water in this work.

\section{Preparation of $\left[\mathrm{Os}(4,4 \text { '-dimethyl-2,2'-bipyridine })_{2}\right.$ (am-py-HA)Cl] $]^{+/ 2+}$}

As shown in Fig. 1, sodium hippurate hydrate and 4aminomethylpyridine were dissolved in $10 \mathrm{~mL}$ ethanolic solution, at reflux and then adding $200 \mathrm{~mL}$ of ethyl ether caused a white powder to precipiate. The conjugation of 4-aminomethylpyridine-HA was verified with the thin-layer chromatography (TLC) and ${ }^{1} \mathrm{HNMR}$ spectroscopy. The osmium complex was prepared by adapting the method reported for the preparation of [Os(4,4'dimethyl-2,2'-bipyridine) $\left.{ }_{2} \mathrm{Cl}_{2}\right]^{2 / 3+}$. 23-27) Typically, $100 \mathrm{mg}$ of $\mathrm{K}_{2} \mathrm{OsCl}_{6}$ and $77 \mathrm{mg}$ of 4,4-dimethyl-2,2-dipyridyl ( 2 equiv) were refluxed in anhydrous ethylene glycol for $30 \mathrm{~min}$. After cooling, $20 \mathrm{~mL}$ of dilute sodium hydrosulfite solution was added and the mixture was chilled. The resulting red-purple crystals were washed with ice water and ethyl ether. Cyclic voltammetry of [Os(4,4'-dimethyl-2,2'bipyridine $\left.)_{2} \mathrm{Cl}_{2}\right]^{2 / 3+}$ showed at $-0.112 \mathrm{~V}$ versus $\mathrm{SCE}$ to verify the product of [Os(4,4'-dimethyl-2,2'-bipyridine $\left.)_{2} \mathrm{Cl}_{2}\right]^{2 / 3+}$. Then $100 \mathrm{mg}$ of [Os(4,4'-dimethyl-2,2'bipyridine $\left.)_{2} \mathrm{Cl}_{2}\right]^{2 / 3+}$ was refluxed with 4-aminomethylpyridine-HA (41.3 mg, 1 equiv) under $\mathrm{N}_{2}$ in anhydrous ethylene glycol for 1 hour. After filtering, the solution was added to $1.5 \mathrm{~L}$ of diethyl ether with vigorously stirring. The product was precipitated and separated by column. Cyclic voltammetry of [Os(4,4'-dimethyl-2,2'-bipyridine) $)_{2}$ (am-py$\mathrm{HA}) \mathrm{Cl}]^{+/ 2+}$ in $0.14 \mathrm{M} \mathrm{NaCl}$ in $\mathrm{pH} 7 \mathrm{PBS}$ buffer showed the Os(II/III) wave at $0.234 \mathrm{~V}$ vs SCE.

\section{Electrodeposition of gold nanoparticles on SPCEs}

As shown in Fig. 2, screen-printed carbon electrodes (SPCEs) were prepared with Electrodag ${ }^{\circledR}$ 423SS (Acheson, Port Hurton, USA) on OHP film using a semiautomatic screen printing machine. Forty microliters of $1.0 \mathrm{mM} \mathrm{KAuCl}_{4}$ in $0.5 \mathrm{M} \mathrm{H}_{2} \mathrm{SO}_{4}$ was loaded onto 3mm-diameter SPCEs. Gold nanoparticles (Au-NP) were electrodeposited by applying a cathodic current at $1.41 \times 10^{-5} \mathrm{~A}$ for 300 seconds using the chronopoten- 


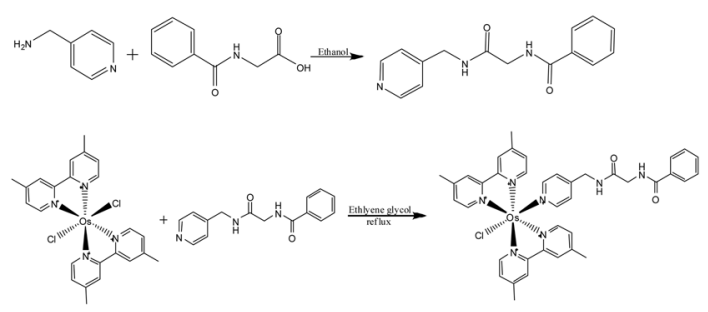

Fig. 1. Preparation of osmium- HA conjugate (Os-HA).

tiometry technique of a CHI 660B Electrochemical Workstation (CH Instruments, TX, USA).

\section{Characterization of Au-NPs on SPCEs}

Au-NPs electrodeposited onto SPCEs were observed with scanning electron microscopy. The typical FE-SEM images of the bare SPCEs are shown in Fig. 2(a) and those of electrodeposited gold nanoparticles on SPCEs are shown in Fig. 2(b, c, d). The average size, shape, and surface density of Au-NPs on SPCEs can be controlled by applying different electrochemical deposition times and cathodic current intensities. Aunanoparticles in the $0.5 \mathrm{M} \mathrm{H}_{2} \mathrm{SO}_{4}$ solution containing $1.0 \mathrm{mM} \mathrm{NaAuCl}_{4}$ were electrodeposited on the SPCEs by applying different cathodic currents such as $1.41 \times 10^{-6} \mathrm{~A}$, $1.41 \times 10^{-5} \mathrm{~A}$ and $1.41 \times 10^{-4} \mathrm{~A}$. In the cathodic current at $1.41 \times 10^{-5} \mathrm{~A}$, the average size of Au-NPs is $70 \pm 20 \mathrm{~nm}$. Finot et al. (1999) reported the effects of tetrachloroaurate (III) ion concentrations and deposition potentials on the size of Au nanocrystals. Au-NPs grew slowly on a glassy carbon surface during the reduction process of $\mathrm{AuCl}_{4}^{-}$ions in acidic solution. However, its average size and surface density increased as electrodeposition time was extended. The Au-NPs growth pattern from our work was similar to that described previously by El-Deab et l. $^{28-30)}$ The Au-NPs on the SPCEs shows to improve the performance of the electrochemical immunoassay. The Au-NPs have a large surface and a good electronic property and provide to access antigen (Os-HA) through all direction to the antibody-HA on the gold nanoparticles. Also, the roughness of SPCE shows better electrical signal. ${ }^{31-32)}$

\section{Measurement principle of the electrochemical immunoassay}

As shown in Fig. 3, the general principle of the HA immunoassay are as follows: (1) $40 \mu \mathrm{L}$ of $10 \mathrm{mM} 3-$ mercaptopropionic acid was pipetted on the SPCEs, (2) $50 \mu \mathrm{L}$ of mixture of $5 \mathrm{mg} / \mathrm{mL}$ EDC and $1 \mathrm{mg} / \mathrm{mL}$ NHS

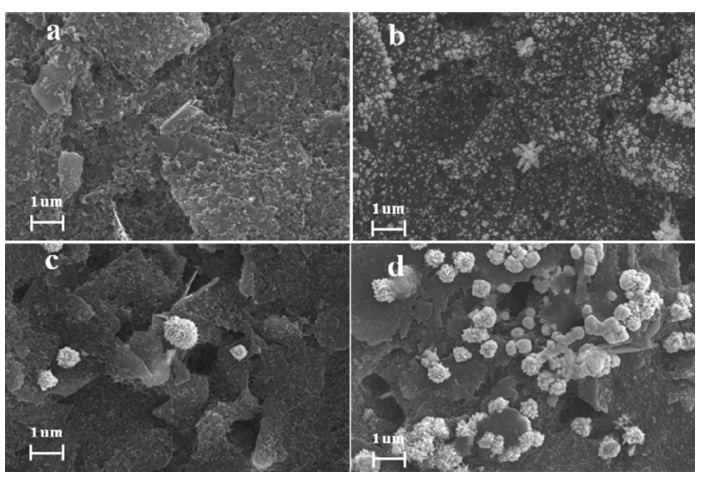

Fig. 2. FE-SEM images on bare SPCEs of $\times 10 \mathrm{~K}$ (a), and those of electrodeposited gold-nanoparticles on SPCE of $\times 10 \mathrm{~K}$ (b), (c) and (d) from $1 \mathrm{mM}$ of $\mathrm{KAuCl}_{4}$ dissolved in $0.5 \mathrm{M}$ $\mathrm{H}_{2} \mathrm{SO}_{4}$ solution. The cathodic currents were $1.41 \times 10^{-5} \mathrm{~A}(\mathrm{~b})$, $1.41 \times 10^{-6} \mathrm{~A}$ (c) and $1.41 \times 10^{-4} \mathrm{~A}(\mathrm{~d})$, for $300 \mathrm{sec}$ using the chronopotentiometry technique.

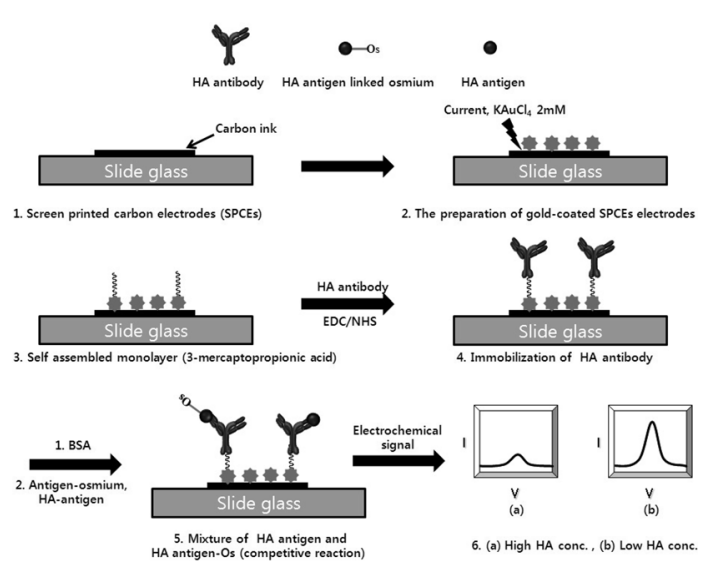

Fig. 3. Schematic diagrams of the reaction of antibody-antigen linked osmium complex on the gold nanoparticles-modified screen printed carbon electrodes (SPCEs).

was added to the electrode, and then the resulting solution incubated for 2 hours at room temperature, (3) $40 \mu \mathrm{L}$ of $1 \mathrm{mg} / \mathrm{mL}$ anti-HA was immobilized with gold nanoparticles on SPCEs, (4) $40 \mu \mathrm{L}$ of the sample solution (a mixture of fixed $2.0 \mathrm{mg} / \mathrm{mL}$ of Os-HA and HA with variable concentration) was introduced by a micropipette, and both of Os-HA and HA competed to bind to anti-HA on the gold nanoparticles. After this reaction, the bounded of Os-HA was measured by the voltammetric (CV, and DPV) techniques. The electrical signals associated with the bounded Os-HA

\section{Electrochemical detection}

Electrochemical measurements were carried out in a 
Faraday cage with a $\mathrm{CH}$ Instruments model $660 \mathrm{~A}$ electrochemical workstation ( $\mathrm{CH}$ Instrument, Austin, TX, USA), interfaced to a computer. The electrochemical characteristics of Os-HA were studied with the $3.0 \mathrm{~mm}$ diameter working electrodes (SPCEs) which were made by screen-printing hydrophilic carbon ink (Electrodag ${ }^{\circledR}$ 423SS from Acheson, Port Hurton, MI, USA) on a flexible polyester film. A counter-electrode consists of $0.5 \mathrm{~mm}$ diameter platinum wire and an $\mathrm{Ag} / \mathrm{AgCl}$ micro-reference electrode (3.0 M KCl saturated with $\mathrm{AgCl}$, Cypress, Lawrence, KS, USA).

\section{Results and Discussion}

\section{Electrochemical characteristics of Os-HA on Au-} NP-deposited SPCEs

Fig. 4 shows typical steady-state cyclic voltammograms of Os-HA on Au-NP-deposited SPCEs as a function of scan rate. The cyclic voltammograms showed quasireversible oxidation and reduction peaks at $\mathrm{E}_{1 / 2}=350 \mathrm{mV}$ (vs. $\mathrm{Ag} / \mathrm{AgCl}$ ). This result suggests that Os-HA has a fast and quasi-reversible redox mediator that can be utilized for an electrochemical immunosensor. The inset in Fig. 6 shows the oxidation $\left[\left(E_{\mathrm{p}}\right)_{\mathrm{a}}\right]$ and the reduction $\left[\left(E_{\mathrm{p}}\right)_{\mathrm{c}}\right]$ peak currents of Os-HA, which increased linearly with the square root of the scan rates $\left(v^{1 / 2}\right)$ in the $10-200 \mathrm{mV} / \mathrm{s}$ range. This finding suggests that the electron transfer process on the electrode is controlled by diffusion. The value of $E^{o}$, for Os-HA ( $350 \mathrm{mV}$ vs. $\mathrm{Ag} / \mathrm{AgCl}$ ) was determined by extrapolating intercept $E_{0.85}$ at $v^{1 / 2}=0 .{ }^{33)}$

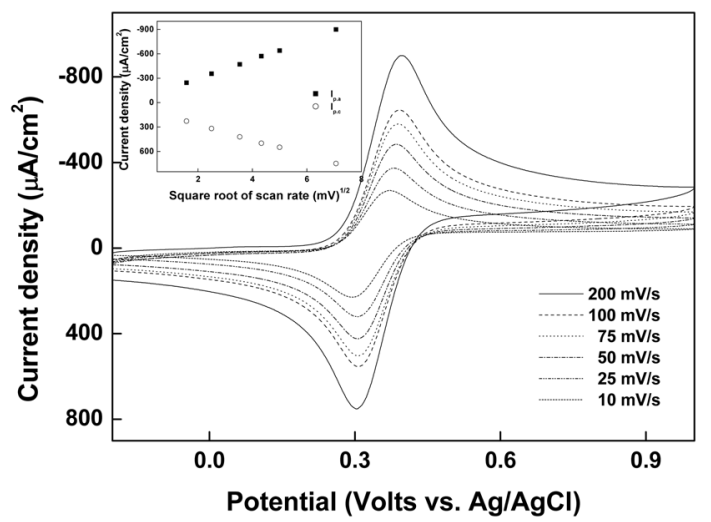

Fig. 4. Cyclic voltammograms of $0.1 \mathrm{mM}$ Os-HA in $100 \mathrm{mM}$ PBS buffer ( $\mathrm{pH} 7.2$ ) with $0.14 \mathrm{M} \mathrm{NaCl}$ at different scan rates $(10,25,50,75,100$, and $200 \mathrm{mV} / \mathrm{s})$ using a Au-NP-deposited SPCEs. Inset : variation of peak current density vs. square root of scan rate. $R_{1}=0.9997$ (square dot), $R_{2}=0.9996$ (circle dot).

\section{Electrochemical detection with HA}

The simple electrochemical immunoassay system is shown in Fig. 3. The antigen-antibody reaction of the Os-HA and Hippuric acid were examined by cyclic voltammetry. Measurements of the antigen-antibody reaction were performed in a solution of fixed $2.0 \mathrm{mg} / \mathrm{mL}$ Os-HA with the electrode. Fig. 5 shows the typical cyclic voltammograms in the electrochemical immunoassay with Os-HA in the presence and absence of HA. Following interaction between HA and Os-HA, and anti-HA, voltammetric signals from Os-HA were directly correlated with HA concentrations. As shown in Fig. 5, a very high current was observed in the absence of HA. This electric signal results from an antigen-antibody interaction between OsHA and anti-HA-coated on the gold electrode. In the presence of HA, low Os-HA peaks result from competition reaction between $\mathrm{HA}$ and Os-HA with antibody-HA on the gold electrode. As shown in the inset of Fig. 5, the current magnitude $\left(\mathrm{i}_{\mathrm{p}, \mathrm{a}}\right)$ at $0.25 \mathrm{~V}$ (vs. $\mathrm{Ag} / \mathrm{AgCl}$ ) was chosen to represent the concentration of HA. The peak current decreased linearly with HA concentration in the $0.1-5 \mathrm{mg} / \mathrm{mL}$ range. Next, the relative concentrations of HA and Os-HA were varied. Measurements in the HA range of $0.1-5 \mathrm{mg} / \mathrm{mL}$ were performed in a solution of fixed $2.0 \mathrm{mg} / \mathrm{mL}$ of Os-HA with a gold electrode. Inset shows the calibration curves at the gold electrode with HA at different concentrations. The detection currents are linear in the HA range of $0.1-5 \mathrm{mg} / \mathrm{mL}$ with a correlation coefficient of 0.9977 . Therefore, quantitative analysis of HA was possible, using the antibody-binding competition

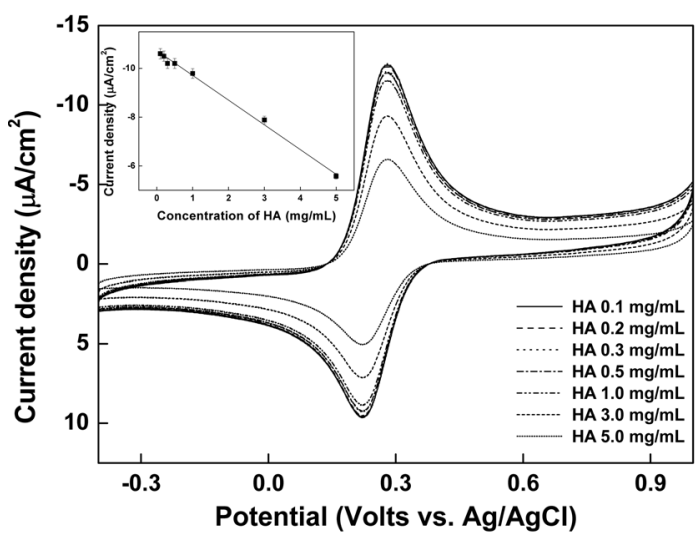

Fig. 5. Cyclic voltammograms of $2.0 \mathrm{mg} / \mathrm{mL}$ Os-HA with variable HA concentration at scan rate of $100 \mathrm{mV} / \mathrm{s}$. Inset: peak currents as a function of the concentration of hippuric acid between 0.1 and $5 \mathrm{mg} / \mathrm{mL}$. $\mathrm{R}=0.9977(\mathrm{~N}=5)$. $\mathrm{N}$ denotes the number of different SPCEs used. 
between HA and Os-HA with the simple electrochemical immunoassay method.

\section{Conclusion}

Simple electrochemical HA immunoassay system was successfully performed, evaluated and show the feasibility for in-field or point-of-care (POC) diagnosis. The advantages of the presented electrochemical immunoassay method include its short time-detection ability and a simple fabrication protocol of chip without need of an expensive instrument. Finally, the proposed electrochemical method can be extended to the applications to detect a wide range of different small antigens in the health care area.

\section{Acknowledgements}

The present research was supported by the research fund of Dankook University in 2008.

\section{References}

1. J.W. Boor and H.I. Hutrig, Ann. Neurol., 2, 440 (1977).

2. N.L. Rosenberg, M.C. Spitz, C.M. Filley, K.A. Davis and H.H Schaumburg, Neurotoxicol. Teratol., 10, 489 (1988).

3. R.G. Feldman, M.H. Ratner and T. Ptak, Environmental Health Perspectives., 107, 417 (1999).

4. H.M. Park, S.H. Lee, H. Chung, O.H. Kwon, K.Y. Yoo, H.H. Kim, S.C. Heo, J.S. Park and G.S. Tae, J. Anal. Toxicol., 31, 347 (2007).

5. P. Kongtip, J. Vararussami and V. Pruktharathikul, J. Chromatogr B Biomed Sci Appl., 751, 199 (2001).

6. K. Tomokuni and M. Ogata, Clin Chem., 18, 349 (1972).

7. T. Sakai, Y. Niinuma, S. Yanagihara and K. Ushio, $J$. Chromatogr, 276, 182 (1983).

8. A.C. Lee, G. Liu, C.K. Heng, S.N. Tan, T.M. Lim and Y. Lin, Electroanalysis., 20, 2040 (2008).

9. Y.Y. Lin, J. Wang, G. Liu, H. Wu, C.M. Wai and Y. Lin, Biosensor and Bioelectronics., 23, 1659 (2008).

10. S. Prabhulkar, S. Alwarappan, G. Liu and C.Z. Li, Biosensor and Bioelectronics., 24, 3524 (2009).
11 S.J. Yoo, Y.B. Choi, J. I. Ju, G. S. Tae, H. H. Kim and S. H. Lee, Analyst., 134, 2462 (2009).

12. J. Wang, A. Ibanez, M.P. Chatrathi and A. Escarpa, Anal Chem., 73, 5323 (2001).

13. C. Duan and M.E. Meyerhoff, Anal Chem., 66, 1369 (1994).

14. T.J. Moore, M.J. Joseph, B.W. Allen, L.A and Jr. Coury, Anal Chem., 67, 1896 (1995).

15. J. Wang, B. Tian and K.R. Rogers, Anal Chem., 70, 1682 (1998).

16. T.K. Lim and T. Matsunaga, Biosens Bioelectron., 16, 1063 (2001).

17. T.K. Lim, S. Imai and T. Matsunaga, Biotechnol Bioeng., 77, 758 (2002).

18. T.K. Lim, H. Ohta and T. Matsunaga, Anal Chem., 75, $3316(2003)$

19. J.M. Nam, C.S. Thaxton and C.A. Mirkin, Science., 301, $1884(2003)$

20. J. Das, M.A. Aziz and H. Yang, J. Am. Chem. Soc., 128, 16022 (2006).

21. S. Purushothama, S. Kradtap, C.A. Wijayawardhana, H.B. Halsall and W.R. Heineman, Analyst., 126, 337 (2001).

22. Y. Zhang and A. Heller, Anal Chem., 77, 7758 (2005).

23. C. Locatelli and G. Torsi, J. Electroanal. Chem., 509, 80 (2001).

24. B.A. Gregg and A. Heller, J. Phys. Chem., 95, 5976 (1991).

25. T.J. Ohara, R. Rajagopalan and A. Heller, Anal. Chem., 66, 2451 (1994)

26. G. Kenausis, C. Taylor, I. Katakis and A. Heller, J. Chem. Soc. Faraday Trans., 92, 4131 (1996).

27. C. Taylor, G. Kenausis, I. Katakis and A. Heller, J. Electroanal. Chem., 396, 511 (1995).

28. Y.-B. Choi and H.-H. Kim, J. Korean. Electrochem. Soc., 10, 152 (2007).

30. M.O. Finot, G.D. Braybrook and M.T. McDermott, $J$. Electrochem. Soc., 466, 234 (1999).

31. M.S. El-Deab, T. Okajima and T. Ohsaka, J. Electrochem. Soc., 150, A851 (2003).

32. Y.-R. Yuan, R. Yuan, Y.-Q. Chai, Y. Zhuo and X.-M. Miao, J. Electroanal. Chem., 626, 6 (2009).

33. S.-F. Liu, X.-H. Li, Y.-C. Li, Y.-F. Li, J-R. Li and L. Jiang, Electrochimica Acta., 51, 427 (2005).

34. E. Steckhan and T. Kuwana, Ber. Bunsenges. Phys. Chem., 78, 253 (1974) 